\title{
PARTNER VIOLENCE AND RISK ASSESSMENT IN CHILD CUSTODY EVALUATIONS
}

\author{
William G. Austin
}

\begin{abstract}
How to integrate the problem of partner violence into a child custody evaluation is analyzed within a risk-assessment approach. The research literature on partner violence is reviewed to examine the issues of establishing a base rate for partner violence and its relative frequencies for both genders. Theoretical typologies of partner violence are reviewed and anew typology presented that is more suitable to the predictive task in the custody evaluation. A model of how the evaluator should approach partner violence is described, with an integration of a risk-assessment approach to child developmental outcomes as associated with custody and parenting time arrangements and a violence risk assessment of a perpetrator/parent.
\end{abstract}

\section{PROBLEM OF PARTNER VIOLENCE AND CHILD CUSTODY}

Spousal maltreatment and violence is a complex and contentious issue that sometimes arises in high-conflict child custody cases. Courts sometimes call on mental health professionals to assist the trier of fact in the decision-making process on child custody and parental access to children. The roles of custody evaluator, mediator/arbitrator, special advocate, special master, and guardian ad litem are occupied by mental health and legal practitioners in this assist role to the judge. The issue of how to address the problem of spousal maltreatment is extremely important in best interests of the child custody determinations (CCDs) because of the demonstrated negative effect on a child's welfare and development from exposure to and witnessing domestic violence (Jaffe \& Geffner, 1998) and exposure to high conflict between parents (Johnston \& Roseby, 1997). Although there are inconsistencies in the research on the behavioral effects on children, this may be due to methodological shortcomings, and it is generally assumed that there is potential for grave developmental effects due to exposure to family violence. When the methodology is improved and database enlarged from multiple sources, negative effects are consistent (Sternberg, Lamb, \& Dawud-Noursi, 1998).

Relatively little guidance is found in the forensic clinical methodology literature on how to integrate the problem of partner violence into a child custody evaluation (CCE) in which the fundamental task is to predict the child's long-term developmental outcomes associated with alternative environmental circumstances due to different custody and parent access arrangements (Austin, 2000a). Gould (1998) and Stahl (1999) provide general frameworks and address issues associated with domestic violence in the context of a CCE. This article attempts to provide a more specific structure for analyzing the partner violence factor in CCEs via a risk-assessment approach to making behavioral predictions in the forensic CCE.

Jaffe and Geffner (1998) reviewed the literature on the negative child effects of spousal violence. Their conclusions were that exposure to partner violence is likely to produce exag-

Author's Note: Correspondence concerning this article should be addressed to William G. Austin, Northwest Colorado Psychological Services, P.O. Box 883009, Steamboat Springs, CO 80488; e-mail: wgaustinphd@yahoo.com. The author acknowledges past fellowship support from the Russell Sage Foundation and University of Virginia School of Law.

FAMILY COURT REVIEW, Vol. 39 No. 4, October 2001 483-496

O 2001 Sage Publications 
gerated behaviors in children above those expected from children in divorcing families who experience high conflict between parents. They proposed that partner violence may produce internalizing symptoms in children such as anxiety, school refusal, psychosomatic symptoms, and nightmares consistent with exposure to trauma.

Externalizing symptoms may include anger, aggression, and a variety of acting-out behaviors. These authors further described a variety of understandable but maladaptive role behaviors exhibited by children from violent homes: attempts to protect the victimized mother and acting as a peacemaker in an attempt to defuse the father's anger in a violent family. Jaffe and Geffner (1998) view partner violence as a general risk factor facing the child. No suggestions were made on how to integrate the problem into a CCE, but suggestions were offered on how to restrict parenting access for the perpetrator of partner violence. Parallel findings are reported by Johnston and Roseby (1997) on characteristics of children from highly conflictual and violent divorcing families. They report developmental disruptions in a number of fundamental domains: separation-individuation with fragmentation of self, sexualized anxiety and gender discomfort, emotional and interpersonal disturbance, and moral development.

The Jaffe and Geffner (1998) review and analysis of partner violence on child custody disputes is weakened by their restricting the analysis to female victimization only. Research shows a high degree of allegations of partner violence among divorcing couples (Newmark, Harrell, \& Salem, 1994) and at nearly equal rates of perceived victimization by both sexes (Straus, 1979). In other populations, research has shown this pattern as well. Among psychiatric populations, the rates of partner violence are approximately equal for frequency and initiation between the sexes (Lidz, Mulvey, \& Gardner, 1993). Survey studies in the United States (Straus \& Gelles, 1986), Canada (Kwong, Bartholomew, \& Dutton, 1999), and New Zealand (Magdol et al., 1997) document the parity of violence between the genders. One-year prevalence rates of approximately $12 \%$ for both sexes were reported by Kwong et al. (1999). Bland and Orn (1986) found 58\% of men and 73\% of women reported initiating the violence when it occurred.

The empirical generalization of parity in the gender distribution of spouse-initiated violence does not diminish the importance of potential differences in the dynamics of male versus female violence initiation. Most studies have not controlled for the level of violence severity. Women are more likely to seek medical attention and report more serious physical injury (Stets \& Straus, 1990) and express more fear of physical injury (Morse, 1995).

The scientific literature thus suggests a need for a more comprehensive framework for examining the problem of crafting appropriate custody and access arrangements appropriate for all subtypes of partner violence, including consideration of bidirectional partner violence. When the child may be exposed to ongoing parental conflict, there is a need for a forensic methodology to accommodate this risk factor for predicting developmental outcomes. This suggestion is made with recognition of research findings and clinical experience that female-partner-initiated violence is likely to cause less physical damage, sometimes be in self-defense, and may be in response to emotional abuse and persistently controlling behavior by the male partner (Holden, Geffner, \& Jouriles, 1998). Clinical theorists and researchers have documented the phenomena of the male batterer (Jacobson \& Gottman, 1998; Walker, 1984), abusive personality in violent intimate relationships (Dutton, 1998), and stalking that can occur after a marital breakup (Walker \& Meloy, 1998). There will be a subset of cases, however, in which the female partner is the principal or sole perpetrator, and many cases of partner violence are likely to be interactive or reciprocal, either in response to the stresses of marital dissolution or as an enduring pattern of partner conflict. Kwong et al. 
(1999) stated: "The majority of respondents in violent relationships reported a pattern of violence that was bidirectional, minor, infrequent, and not physically injurious" (p. 150). There are external validity problems both with studies of clinical samples of battered women and representative surveys. The former may overestimate the frequency of the extreme forms of violence; the latter may underestimate the extreme forms because they are rare in the survey samples (Kwong et al., 1999; Straus, 1990).

Standard of practice guidelines indicate that custody evaluators need to take a family system approach and to be open to all hypotheses on a given issue (Gould, 1998). Thus, partner violence needs to be examined in its full context and not limited to male-partner-initiated violence. A faulty preconception by custody evaluators can create clinical blinders and not produce a forensic-scientific work product that is more likely to contain accurate predictions on developmental outcomes. The scientific evidence documents the existence of bidirectional or reciprocal partner violence (Kwong et al., 1999; Lidz et al., 1993; Stets \& Straus, 1990; Straus \& Gelles, 1986) and a widely accepted typology of partner violence includes "female-initiated" and "interactive" violence as two of the five types (Johnston \& Campbell, 1993). This empirical generalization is applicable to the wider population of industrialized nations and not just to psychiatric populations. Kwong et al. (1999) stated, "Sixty-two percent of men and 52\% of women who reported violence indicated that it was perpetrated by both partners" (p. 156). Lidz et al. (1993) concluded that clinicians who are supposed to make violence risk assessments generally tend to underestimate the rate of female-initiated violence. Both the partner violence prevalence and violence risk assessment studies thus identify the need for researchers and clinicians to be mindful to all subtypes of violence while at the same time being most aware of signs of the extreme subtypes in which physical injury can be severe.

\section{TYPOLOGIES OF PARTNER VIOLENCE SCENARIOS}

Johnston and Campbell (1993) proposed the following descriptive scheme to differentiate types of violent intimate partner relationships:

- Ongoing or episodic male battering;

- Female-initiated violence;

- Male-controlling interactive violence;

- Separation-engendered violence/postdivorce trauma;

- Psychotic and paranoid reactions leading to violence.

These subtypes of partner violence are useful to mental health and legal professionals because they suggest common behavioral patterns and needs of children when they are exposed to the particular family dynamics in each subtype. The modal characteristics of parents found in a subtype help establish an outlook for change that is necessary for more effective parenting. Each scenario provides suggestions on interventions to control the violence. They also provide a framework for constructing predictions in the CCE. For example, in the male battering subtype, it is expected that the male perpetrator has a personality disorder with traits of narcissism, low frustration tolerance, low impulse control, and a need to dominate and control his partner. The custody evaluator will want to focus on the stable personality trait and its likely resistance to change. In the female-initiated subtype, the male partner may be passive-aggressive, intellectualizing, and depressed, and is likely to provoke his part- 
ner who, in turn, may have traits of histrionic behaviors, dependency, emotional unpredictability, and self-preoccupation (Johnston \& Campbell, 1993).

A more parsimonious descriptive system has been proposed by Johnson (1995), who dichotomized partner violence into "patriarchal terrorism" and "common couple violence" subtypes. His system emphasizes the controlling, physically and emotionally brutalizing example of male battering versus a bidirectional, interactive violence generally characterized by violence of a low level of severity.

Partner violence typology. These typologies are helpful to the clinician who is constructing therapeutic interventions. For the custody evaluator whose task is predictive accuracy, I propose a different, multidimensional typology that will lend itself to a more exact measurement of variables relevant to the prediction of violence and developmental outcomes for the child. This typology reflects the scientific research on frequencies of partner violence, major risk factors for violence, and level of violence. The six dimensions include temporal pattern of violence, sex of perpetrator, severity of physical violence, verbal versus physical aggression, presence of major risk factors for violence potential, and whether the child was exposed to the violence. I propose that an examination of the combination of these variables creates a more efficient method of making behavioral predictions relevant to custody evaluators' task. It also becomes easier to communicate a risk assessment to the court by combining these dimensions to portray the family context of the violent behavior.

The following scheme describes the variables and the gradients for each dimension.

1. Temporal dimension

Reactive (to relationship separation), single incident

Reactive, reciprocal or bidirectional violence, multiple incidents

Enduring, chronic consistent or episodic pattern of violence

2. Sex of perpetrator and causal direction of violence

Male, instigator

Female, instigator

Bidirectional, mutual

Bidirectional, mostly male

Bidirectional, mostly female

3. Severity of physical harm (operationalized via the Conflict Tactics Scale) (Straus, 1979)

Mild (threw something, pushed, grabbed, or shoved)

Moderate (kicked, bit, or slapped)

Severe (hit with fist, hit or tried to hit with something, beat up, choked, threatened with knife or gun, used a knife or gun)

4. Type of aggression

Verbal provocation

Physical violence

5. Presence of major risk factors

Presence or absence of alcohol use during violence

Presence or absence of substance abuse during violence

Presence of alcohol or substance abuse as an ongoing mental disorder

Presence or absence of major mental disorder (bipolar disorder; schizophrenia or other psychotic state; personality disorder)

History of violent behavior in other settings

6. Children exposed to violence

Children exposed

Children not exposed 
This typology presents a system with utility by its face validity for the court and its efficiency for making predictions by the evaluator with a combination of risk factors. It combines research-based actuarial factors with clinical skill, or what has been called the "guided clinical approach" in the violence risk assessment literature (Hanson, 1998). Its practical utility forms case questions: What is the predictive value of unidirectional, chronic, moderate severity, involving major mental disorder and substance abuse, and children exposed? Or, reactive, several incidents, bidirectional, mild severity, involving bipolar disorder in one parent, and children exposed only to verbal aggression? The typology also incorporates gradations of severity on the dimensions to facilitate clinical-forensic predictions in contrast to the dichotomous system of Johnson (1995) or the categorical system of Johnston and Campbell (1993). In a given case, when partner violence is relevant to the questions of custody and access, the evaluator can identify the subtype of partner violence in a straightforward manner for the court. For example, when the partners engaged in reactive, bidirectional violence of pushing in one incident, alcohol or substance abuse was not involved, there is not a history of violence in other settings, and there is not a major mental disorder or substance abuse/alcohol disorder, then the violence will not be considered relevant in the custody evaluation. In contrast, when there is an enduring pattern of violence and major risk factors are present, then the factor will be heavily weighted in a CCE. Predictions and recommendations of custody and access will depend on the type and level of violence and its causal direction (unitary or bidirectional). The typology requires the use of information gathered by the skilled clinician who has training in techniques and knowledge of research on violence risk.

Theoretical rationale for dimensions. First, the dimension of a temporal understanding of the violence places the factor in the context of the relationship and family history. The extreme case of unitary and chronic abuse by one partner lies at one extreme versus a single incident in reaction to the relationship breakup at the other extreme.

Second, the causal direction of violence is important in understanding the family dynamics as they relate to parenting effectiveness. One could encounter the case of two involved but contentious parents who frequently engage in reciprocal low-level violence versus a primary caretaker mother who episodically instigates physical violence versus a father who gets physically violent when intoxicated about twice per month.

Third, the severity of physical violence is important in understanding the potential harm to children and adult victims. This helps define the clinical context when, in contrast, surveys have not generally studied the effect of severity.

Fourth, the distinction between verbal aggression and physical violence addresses the conceptual and clinical overlap between the high conflictual but nonviolent instigator versus the reactionary violent perpetrator in response to verbal aggression. One partner may push the emotional trigger; the other may react physically. Given the research data on gender parity in the initiation of violence, it is expected that the predominantly verbal versus physical instigation may be equally distributed as well. This information is valuable in attempting to craft workable parenting access schedules for highly conflictual couples. It juxtaposes emotional and physical abuse.

Fifth, the inclusion of major risk factors goes to the heart of one of the principal clinical tasks for the custody evaluator: to make predictions of violence risk potential for one or both parents. Research from the violence risk-assessment literature establishes the strong predictive power of major mental disorder, substance abuse and alcohol dependence, and history of aggressive and violent acts in other contexts ( Lidz et al., 1993; Skeem, Mulvey, \& Lidz, 2000 ). They elicit questions relevant to intervention, treatment, and prognosis for change. 
The evaluation of mental and substance abuse/alcohol disorders may prove pivotal in predicting potential for the rare and severe violent event in reaction to the end of the marriage, spousal and child homicide. The rejection and narcissistic injury in this context can be lethal. ${ }^{1}$

Fifth, the presence of children in direct observation or indirectly exposed to conflict and violence provides direct evidence on parenting judgment.

\section{LEGAL CONTEXT OF PARTNER VIOLENCE}

There has been an evolution of state statutory law in the United States in recognizing the need for legal control of partner violence generally and its significance for child custody determinations in particular. More than two dozen states now have mandatory arrest statutes when police officers are called to a residence in a domestic dispute. The Colorado Revised Statutes, as an example, has this mandate (Offenses Involving Family Relations, 1999). It further allows for temporary custody of a child to be awarded to a third party if it is predicted the child may be exposed to spousal abuse (Dissolution of Marriage-Parental Responsibilities, $1999 \mathrm{a})$. In the context of child custody disputes, the Colorado statute requires a party to disclose all prior restraining orders related to spousal abuse (Dissolution of Marriage-Parental Responsibilities, 1999b), and there is a presumption against joint custody (or shared parenting responsibility) if there has been a conviction for spousal abuse (Dissolution of Marriage-Parental Responsibilities, 1999c), and it will be a relevant factor for parenting time determinations (Dissolution of Marriage-Parental Responsibilities, 1999d). This presumption is also proposed in a model statute by the National Council of Juvenile and Family Court Judges (1994). One "unexpected" finding of partner violence laws has been the increasing number of arrests of women. In California, with a "primary aggressor" law, 16\% of arrests in 1998 were women (Clifford, 1999), which further points to the need to consider interactive or bidirectional dynamics in partner violence.

\section{CLINICAL-FORENSIC-SCIENTIFIC PARADIGM}

\section{FORENSIC FRAMEWORK}

Recent writings on clinical methodology for CCEs (Gindes, 1995; Gould, 1998, 2000; Schutz, Dixon, Lindenberger, \& Ruther, 1989; Stahl, 1994, 1999) in combination with guidelines published by professional organizations (American Psychological Association, 1994; Association of Family \& Conciliation Courts, 1995; Committee on Ethical Guidelines Forensic Psychologists, 1991; North Carolina Psychological Association, 1994) provide a framework for the emergent paradigm on how to approach these evaluations. The custody evaluation is now constructed as one type of forensic evaluation, namely, the application of theory, research, and scientific method to legal questions before a court (Gould, 1998, 2000). The task of the evaluator in the new paradigm is to present detailed observations in a scientific case study of the family system, explain relationships between relevant factors or predictive variables, and make predictions on the effects of differential environmental circumstances associated with custody and access arrangements on the developmental outcomes for the child. The properly designed and implemented CCE should be verifiable by other evaluators with respect to interpretation and prediction of developmental outcomes. 
The expectation of a scientific work product in the CCE is consistent with the trend among states (Shuman, 1997) to adopt the stricter federal standards of evidence for expert testimony (Daubert v. Merrell Dow Pharmaceuticals, 1993; General Electric v. Joiner, 1997; Kumho Tire. Inc. v. Carmichael, 1999). In this context, the evaluator must be able to justify his or her hypotheses, choice of independent variables, clinical methodology, operationalization of the dependent or outcome variables for the child's long-term development, use of relevant scientific research, and the rational basis for behavioral predictions. The sophisticated attorney will want to put a report through a rigorous forensic qualitycontrol test on the clarity in articulation of hypotheses, measurement of factors, robustness and precision of methods, and the correspondence between data and interpretation. (For an analysis of evidentiary standards and admissibility of behavioral science testimony, see Krauss \& Sales, 1999; Shuman \& Sales, 1999; Tenopyr, 1999).

\section{RISK ASSESSMENT APPROACH TO CCE}

I have recently reconceptualized the task of the CCE in terms of risk assessment on the potential for developmental harm to the child associated with divorce (Austin, 2000a) or relocation (Austin, 2000b, 2000c). This view of seeing the task of evaluator and decision making as one of first predicting potential detriments associated with custody and access is particularly appropriate when there is alleged or verified partner violence or other types of domestic violence, abuse, or neglect. When violence becomes the salient factor in $\mathrm{CCD}$, the analysis will turn on the conceptual obverse of best interests of the child, or predicting potential harm. The evaluator's role also includes making risk-reduction interventions: therapy, parent education, access schedules, parenting time supervision, and controlled contact between parents.

The risk-assessment approach provides an alternative analytical scheme to be integrated into the normal evaluation procedures. The evaluator initially will measure the same types of variables: relationship/attachments between family members, psychological status of all parties, special developmental needs, parenting effectiveness, resources of the child, child's demonstrated resilience, and social supports from other parties. The risk-assessment component then directs the evaluator to measure risk factors, protective factors, and to address the issue of potential prediction errors and their possible consequences (Austin, 2000b, 2000c). Risk factors in the CCE for violent families include those contained in the partner violence typology, with attention paid to the subtype, or combination of the six variables. Risk factors in the typology are the type of violence, severity of violence, temporal pattern, and presence of one or more of the major risk factors for violence (major mental disorder, substance abuse and/or alcohol disorder, and history of violence in other settings), and parent violence in front of the children. Other risk factors may include special developmental needs of the child; poor coping with divorce by child; negative relationship or attachment problems between child and parent or parents; inability of one parent to promote the child relationship with other parent; signs of parental alienation; economic hardship; physical living condition of a parent's residence; and negative attitude toward a new significant other. Protective factors include the inverse of some risk factors such as strong emotional bond between child and parent; good predivorce level of functioning by child; strong psychological resources by child, especially intellectual level; ability of parents to work together on parenting despite a history of violence; and general high ratings on parenting effectiveness.

The evaluator's predictions of the child's developmental outcomes is guided by combining risk and protective factors. Predictions and recommendations should be presented to the 
court in probabilistic rather than dichotomous language. The probabilistic statement reflects the evaluator's level of confidence based on the data (Austin, 2000c).

\section{GATHERING CLINICAL INFORMATION ON VIOLENCE}

Violence risk assessment and CCE. The risk assessment for a CCE for the violent family involves a three-step process. The evaluator must first conduct a violence risk assessment (VRA) on one or both parents. This requires the evaluator to be trained in these clinical techniques and have underlying research knowledge on violence in intimate relationships (Heilbrun \& Heilbrun, 1995; Quinsey, Harris, Rice, \& Cormier, 1998; Webster, Harris, Rice, Cormier, \& Quinsey, 1994). The clinical data should include structured interviews; psychological testing, including a personality inventory such as a the Minnesota Multiphasic Personality Inventory- 2 and projective personality testing (Rorschach); collateral information; and special instruments such as the Spousal Risk Assessment Guide (Kropp, Hart, Webster, \& Eaves, 1999), the Revised Psychopathy Checklist (Hare, 1991), and Violence Risk Assessment Guide (Harris, Rice, \& Quinsey, 1994). Part of the VRA will be an assessment of the credibility of the allegations of violence if the facts are in dispute.

The second step is to integrate the VRA findings into the CCE, where the degree of predicted risk to the child due to exposure to violence is balanced with other factors. When there is a significant degree of violence risk, it will become a salient and heavily weighted factor in addressing issues of custody and access.

The third step is to address interventions that will reduce the risk of harm. Researchers have grouped risk factors into static and dynamic factors (Heilbrun \& Heilbrun, 1995). Static refers to factors that resist change (personality or substance-abuse disorder refractory to treatment, history of violence). Dynamic factors are those that are more fluid or situational and contain a better prognosis for change (reactive form of partner violence, psychological disorder amenable to change, parenting deficit). Risk-reduction interventions are integrated into recommendations to the court: anger management treatment, parenting instruction, and parental contact rules to safeguard child from conflict or violence.

Discrepant reports on violence. Research has uncovered discrepancies in violence reporting between males and females, suggesting that it may be difficult to ascertain the true subtype and dynamics of partner violence in a given case. The pattern of discrepancies is complex and difficult to clearly interpret. Some studies show a low rate of agreement between partners, which suggests underreporting of violence by husbands of husband-initiated violence (Jouriles \& O'Leary, 1985; Langhinrichsen-Rohling \& Vivian, 1994; Szinovacz, 1983). Sternberg et al. (1998) concluded their literature review with the statement, "All researchers agree that the apparent prevalence of spousal violence varies depending on whether husbands or wives are informants, particularly when agreement about specific violent incidents are at issue" (pp. 125-126). They interpret the literature as showing why it is important to use multiple informants to try to increase reliability in the data on the issue of violence.

The findings from representative surveys of partner violence provide contrasting patterns of data on the issue of discrepant reporting of violence. Kwong et al. (1999), with a sample size of 707, found striking gender agreement for frequency of occurrence at all levels of violence severity on the indices of one-year prevalence. They also found males to report slightly higher, but not statistically significant, rates of male- to female-instigated violence in con- 
trast to the clinical research sample above that found evidence of underreporting by male perpetrators. Kwong et al. (1999) found the perhaps counterintuitive finding that "men generally reported gender equality in the perpetration receipt, initiation, and bidirectionality of abuse ... women tended to report that they were more likely to perpetrate violent acts than their male partners" (p. 157). The authors acknowledge that the findings may reflect women underreporting violence when they are the victim, but the overall findings contradict the conclusions of Sternberg et al. (1998) and others of stark gender differences in reporting.

The differences between survey and clinical studies may be due to several reasons. First, the clinical samples are likely to contain a higher level of psychological disturbance and more entrenched family conflict (e.g., couples involved in marital therapy) (Jouriles \& O'Leary, 1985), where biased reporting might be expected. Second, the relatively small sample sizes in the clinical samples are subject to statistical distortion due to potential influence of extreme scores on derived mean scores, grossly different group sample sizes between clinical and community groups (e.g., Jouriles \& O'Leary, 1985), and unstable estimates due to small sample size per se. It can be argued that when there is a large representative sample in which severity level and causal direction is measured for both partners, then the rate of agreement should be high and prevalence of partner violence substantial (e.g., 10\% to 12\%) (Kwong et al., 1999).

Although violence reporting may be more reliable than previously thought, this does not imply that there will not be self-interested distortions of violence reports for the complex child custody case involving domestic violence. When the case cannot be mediated or settled and a CCE is ordered, it is expected that there will be a highly contentious quality to the case, in which information manipulation may be common. The mandatory arrest statutes further suggest that it will not be uncommon to encounter cases of reactive aggression associated with a marital breakup. In these subtypes of partner violence, the severity and causal direction may be ambiguous. A bidirectional altercation with minor severity would be a common subtype (Kwong et al., 1999), and the dynamics may include one partner being verbally aggressive and with the other partner responding with physical force. The task of the evaluator is to unravel the past scenarios of aggression and violence and the implications for the children in a changed family structure with custody and parenting access.

Studies have also suggested significant discrepancies on parent estimates of exposure of children to partner violence and children reports (Dobash \& Dobash, 1984; Hughes, Parkinson, \& Vargo, 1989; O'Brien, John, Margolin, \& Erel, 1994). Parents tend to underestimate the frequency of child exposure. Sternberg et al. (1998) concluded it is likely children are exposed to parent violence much of the time, and parents apparently are either unaware or motivated to minimize the extent of exposure.

Dealing with biased data. Recent publications emphasize the need to use multiple informants or collateral sources in investigating the extent and nature of partner violence in a family. Drawing on multiple data sources is proposed for gathering reliable research data for understanding family violence of all types (Sternberg et al., 1998), dealing with situations of unverified allegations of partner violence (Austin, 2000d), and using a system for deciphering the potential for bias and distortion (Austin, in press). The methodological rule in these articles is to demand that the evaluator employ multiple data sources to achieve convergent and discriminant verification of the relevant hypotheses in the case on the issue of violence. The interpretive task is generally one of triangulation, in which the evaluator examines degrees of congruency between separate sources of information, with more weight afforded sources who hold greater perceived neutrality (Austin, in press; Heilbrun \& Warren, 1999). 
In an earlier article (Austin, 2000d), I outlined a framework for assessing credibility in allegations of partner violence when the facts are in dispute. ${ }^{2}$ The evaluator needs to draw on divergent sources of information to determine the likelihood that violence occurred and to what extent. These sources of information include the following:

- Objective verification from records (medical and police).

- Pattern of abuse complaints; did allegations surface only in the context of a child custody case?

- Corroboration by credible others.

- Absence of disconfirming verbal reports by credible third parties.

- Psychological profile and past history of abusive behavior by the alleged perpetrator of marital violence.

- Psychological status of the alleged victimized partner.

The custody evaluator who works on the complex issue of family violence needs to develop a system for dealing with biased data in both the VRA stage and the CCE stage. Mental health professionals are not more skilled at deciphering the truth than others based on clinical impressions (Eckman \& O'Sullivan, 1991). The six factors listed above are an attempt to provide discrete data sources that can create a triangulation of reasoning on the issue of violence. The result should be a larger database and clearer perspective, not just on the issue of whether violence occurred in the marital relationship, but the subtype, degree, pattern, and presence of children.

In another article (Austin, in press), I added to the development of a system for interpreting potentially biased data. In addition to examining the six sources of information, the evaluator can engage in a process of cleaning up the data by comparing congruencies and discrepancies in the data between the divergent data sources. This system proposes the following approach to utilizing collateral sources of information:

- Ascertain the informational value of a collateral source: access to critical information and/or a breadth of material about child and family.

- Establish the ostensible credibility of the source from the degree of neutrality or nonalignment with the litigating parents.

- The discriminative value of the collateral information will be a product of the informational value and credibility.

- The convergent validity of the information will be a product of agreement with a parent and the discriminative value.

The evaluator should strive for a goal of a compiling a comprehensive data set on a family that can be examined for bias and distortion. Issues such as partner violence enhance the dangers of self-interested bias, distortion, and manipulation. It is proposed that an important part of the standard of forensic practice for CCEs should be a systematic method of trying to control these errors in the data by using divergent sources of information and evaluating their ultimate convergent value. The six sources of information and the triangulation analysis to increase convergent validity of data on the clinical hypotheses are proposed as one framework to use. In some cases, the evaluator will not be able to derive an unambiguous picture on the issue of violence. The evaluator will not be able to hold a clear opinion or make a prediction on the risk associated with violence. There are limits to truth-finding. In this case, the court will be better equipped to deal with the issue through the adversarial fact-finding process. 


\section{CLINICAL PRAGMATICS: QUESTIONS FOR THE EVALUATOR}

When the issue of partner violence is raised as a relevant factor in a CCE, the evaluator will want to ask the following questions and choose clinical methods to answer them:

1. Was there partner violence or other types of family violence?

2. Are the facts in dispute on the violence issue?

3. When did the allegations of violence first surface?

4. If the allegations are verified, what is the subtype of partner violence? This will yield information on the pattern, type, severity, causal pattern (who initiates), and if children were exposed. What does the subtype imply for future harm or emotional security to the child?

5. If the allegations are in dispute, what system will be used to sort out the potential bias in the data?

6. Is the violence likely to recur in the new family living arrangements?

7. What risk and protective factors are present in the family system?

8. What custody and access arrangements will work best to lower the risk of harm to the child in light of the violence?

9. What is the likelihood of change? Is the perpetrator or perpetrators amenable to treatment? Are they taking responsibility for the misconduct? Are the relevant risk factors mostly static or dynamic?

\section{NOTES}

1. The potential lethality of partner violence is well documented (Showalter, Bonnic, \& Roddy, 1980). The risk assessment in the child custody evaluation needs to address the possibility of homicide or serious bodily injury associated with contact between conflictual parents and alterations in parenting access schedules. Several murder-suicide cases within the context of custody and access disputes occurred in Colorado within the same year (Cornelius, 2000).

2. This system can also be applied to allegations of sexual abuse when there is an absence of positive medical findings or eyewitness evidence.

\section{REFERENCES}

American Psychological Association. (1994). Guidelines for child custody evaluations in divorce proceedings. American Psychologist, 49, 677-679.

Association of Family \& Conciliation Courts. (1995). Model standards of practice for child custody evaluation. Madison, WI: Author.

Austin, W. G. (2000a). Behavioral inference and legal calculus in child custody. Manuscript submitted for publication.

Austin, W. G. (2000b). A forensic psychology model of risk assessment for the child custody relocation law. Family and Conciliation Courts Review, 38, 192-207.

Austin, W. G. $(2000 \mathrm{c})$. Relocation law and the threshold of harm: Integrating legal and behavioral perspectives. Family Law Quarterly, 34, 63-82.

Austin, W. G. (2000d). Assessing credibility in allegations of marital violence in the high-conflict child custody case. Family and Conciliation Courts Review, 38, 462-477.

Austin, W. G. (in press). Guidelines for utilizing collateral sources of information in child custody evaluations. Family Court Review.

Bland, R., \& Orn, H. (1986). Family violence and psychiatric disorder. Canadian Journal of Psychiatry, 1, 129-137.

Clifford, J. O. (1999, November 25). Domestic laws nab women: Primary 'aggressor' results surprising. The Denver Post, p. A9. 
Committee on Ethical Guidelines for Forensic Psychologists. (1991). Speciaity guidelines for forensic psychologists. Law and Human Behavior, 15, 655-665.

Comelius, C. (2000, January 30). A massacre on unsafe ground: Warring couple rejected plan to transfer kids at neutral site. The Denver Post, pp. Al, A5.

Daubert v. Merrell Dow Pharmaceuticals, Inc., 509 U.S. 579 (1993).

Dissolution of Marriage - Parental Responsibilities (1999a). C.R.S. \$14-10- 124(2.5).

Dissolution of Marriage - Parental Responsibilities (1999b). C.R.S. \$14-10- 123.6.

Dissolution of Marriage - Parental Responsibilities (1999c). C.R.S. \$14-10-124(1)(b)(V).

Dissolution of Marriage - Parental Responsibilities (1999d). C.R.S. §14-10-124(1)(a)(X).

Dobash, R. E., \& Dobash, R. P. (1984). The nature and antecedents of violent events. British Journal of Criminology, 24, 269-288.

Dutton, G. (1998). The abusive personality: Violence and control in intimate relationships. New York: Guilford.

Eckman, P., \& O'Sullivan, M. (1991). A few can catch a liar. American Psychologist, 46, 913-920.

General Electric v. Joiner, 117 S.Ct. 1243 (1997).

Gindes, M. (1995). Guidelines for child custody evaluations for psychologists: An overview and commentary. Family Law Quarterly, 29, 39-62.

Gould, J. W. (1998). Conducting scientifically crafted child custody evaluations. Thousand Oaks, CA: Sage.

Gould, J. W. (2000). Scientifically crafted child custody evaluations. Part Two: A paradigm for forensic evaluations. Family and Conciliation Courts Review, 37, 159-178.

Hanson, R. K. (1998). What do we know about sex offender risk assessment? Psychology, Public Policy, and Law, 4, 50-72.

Hare, R. (1991). The Hare Psychopathy Checklist-Revised. Toronto, Ontario, Canada: Multi-Health Systems.

Harris, G. T., Rice, M. E., \& Quinsey, V. L. (1994). Violent recidivism of mentally disordered offenders: The development of a statistical prediction instrument. Criminal Justice and Behavior, 20, 315-335.

Heilbrun, K., \& Heilbrun, A. B. (1995). Risk assessment with the MMPI-2. In Y. S. Ben-Porath, J. R. Graham, G.C.N. Hall, R. D. Hirschman, \& M. S. Zaragoza (Eds.), Forensic applications of the MMPI-2 (pp. 160-178). New York: Springer.

Heilbrun, K., \& Warren, J. (1999, May). Third party information in forensic assessment. Workshop sponsored by the American Academy of Forensic Psychology, Philadelphia, PA.

Holden, G. W., Geffner, R., \& Jouriles, E. N. (Eds.). (1998). Children exposed to marital violence: Theory, research, and applied issues. Washington, DC: American Psychological Association.

Hughes, H. M. (1988). Psychological and behavioral correlates of family violence in child witnesses and victims. American Journal of Orthopsychiatry, 58, 77-90.

Hughes, H. M., Parkinson, D., \& Vargo, M. (1989). Witnessing spouse abuse and experiencing physical abuse: A "double whammy?" Joumal of Family Violence, 4, 197-209.

Jacobson, N., \& Gottman, J. (1998). When men batter women: New insights into ending abusive relationships. New York: Simon \& Schuster.

Jaffe, P. G., \& Geffner, R. (1998). Child custody disputes and domestic violence: Critical issues for mental health, social service, and legal professionals. In G. W. Holden, R. A. Geffner, \& E. N. Jouriles (Eds.), Children exposed to marital violence: Theory, research, and applied issues (pp. 371-408). Washington, DC: American Psychological Association.

Johnson, M. P. (1995). Patriarchal terrorism and common couple violence: Two forms of violence against women. Journal of Marriage and the Family, 57, 283-294.

Johnston, J. R., \& Campbell, L.E.G. (1993). A clinical typology of interparental violence in disputed custody divorces. American Journal of Orthopsychiatry, 63, 190-199.

Johnston, J., \& Roseby, V. E. (1997). In the name of the child: A developmental approach to understanding and helping children of conflicted and violent divorce. New York: Free Press.

Jouriles, E. N., \& O'Leary, K. D. (1985). Interspousal reliability of reports of marital violence. Journal of Consulting and Clinical Psychology, 53, 419-421.

Krauss, D. A., \& Sales, B. D. (1999). The problem of "helpfulness" in applying Daubert to expert testimony: Child custody determinations in family law as an exemplar. Psychology, Public Policy, and Law, 5, 78-99.

Kropp, P. R., Hart, S. D., Webster, C. D. \& Eaves, D. (1999). Spousal assault risk assessment guide. Toronto, Ontario, Canada: Multi-Health Systems and B. C. Institute Against Family Violence.

Kumho Tire, Inc. v. Carmichael, 119 S.Ct. 1167 (1999).

Kwong, M. J., Bartholomew, K., \& Dutton, D. G. (1999). Gender differences in patterns of relationship violence in Alberta. Canadian Journal of Behavioral Science, 31, 150-160. 
Langhinrichsen-Rohling, J., \& Vivian, D. (1994). The correlates of spouses' incongruent reports of marital aggression. Joumal of Family Violence, 9, 265-283.

Lidz, C. W., Mulvey, E. P., \& Gardner, W. (1993). The accuracy of predictions of violence to others. Journal of the American Medical Association, 269, 1007-1011.

Magdol, L., Moffitt, T. E., Caspi, A., Newman, D. L., Fagan, J., \& Silva, P. A. (1997). Gender differences in partner violence in a birth cohort of 21-year-olds: Bridging the gap between clinical and epidemiological approaches. Journal of Consulting and Clinical Psychology, 65, 68-78.

Morse, B. J. (1995). Beyond the Conflict Tactics Scale: Assessing gender differences in partner violence. Violence and Victims, 10, 251-272.

National Council of Juvenile and Family Court Judges. (1994). Model statute on child custody. Reno, NV: Author.

Newmark, L., Harrell, A., \& Salem, P. (1994). Domestic violence and empowerment in custody and visitation cases: An empirical study on the impact of domestic abuse. Madison, WI: Association of Family and Conciliation Courts.

North Carolina Psychological Association. (1994). Child custody guidelines. Raleigh, NC: Author.

O'Brien, M., John, R. S., Margolin, G., \& Erel, O. (1994). Reliability and diagnostic efficacy of parents' reports regarding children's exposure to marital aggression. Violence and Victims, 9, 45-62.

Offenses Involving the Family Relations, C.R.S. \$18-6-803.6(l) (1999).

Quinsey, V. L., Harris, G. T., Rice, M. W., \& Cormier, C. A. (1998). Violent offenders: Appraising and managing risk. Washington, DC: American Psychological Association.

Schutz, B. M., Dixon, E. B., Lindenberger, J. C., \& Ruther, N. J. (1989). Solomon's sword: A practical guide to conducting child custody evaluations. San Francisco: Jossey-Bass.

Showalter, C. R., Bonnie, R. J., \& Roddy, V. (1980). The spousal-homicide syndrome. Journal of Law and Psychiatry, 3, 117-141.

Shuman, D. W. (1997). What should we permit mental health professionals to say about "The best interests of the child"?: An essay on common sense, Daubert, and the rules of evidence. Family Law Quarterly, 31, 551-570.

Shuman, D. W., \& Sales, B. D. (1999). The impact of Daubert and its progeny on the admissibility of behavioral and social science evidence. Psychology, Public Policy, and Law, 5, 3-15.

Skeem, J. L., Mulvey, E. P., \& Lidz, C. W. (2000). Building mental health professionals' decisional models into tests of predictive validity: The accuracy of contextualized predictions of violence. Law and Human Behavior, 24, 607-628.

Stahl, P. (1994). Conducting child custody evaluations: A comprehensive guide. Thousand Oaks, CA: Sage.

Stahl, P. (1999). Complex issues in child custody evaluations. Thousand Oaks, CA: Sage.

Stemberg, K. J., Lamb, M. E., \& Dawud-Noursi, S. (1998). Using multiple informants to understand domestic violence and its effects. In G. W. Holden, R. A. Geffner, \& E. N. Jouriles (Eds.), Children exposed to marital violence: Theory, research, and applied issues (pp. 121-156). Washington, DC: American Psychological Association.

Stets, J. E., \& Straus, M. A. (1990). Gender differences in reporting marital violence and its medical and psychological consequences. In M. A. Straus \& R. J. Gelles (Eds.), Physical violence in American families: Risk factors and adaptations to violence in 8,145 families (pp. 227-244). New Brunswick, NJ: Transaction Publishing.

Straus, M. A. (1979). Measuring intrafamily conflict and violence: The Conflict Tactics (CT) Scales. Journal of Marriage and the Family, 41, 75-88.

Straus, M. A. (1990). Injury and the frequency of assault and the "Representative Sample Fallacy" in measuring wife beating and child abuse. In M. A. Straus \& R. J. Gelles (Eds.), Physical violence in American families: Risk factors and adaptations to violence in 8,145 families (pp. 75-91). New Brunswick, NJ: Transaction Publishing.

Straus, M. A., \& Gelles, R. J. (1986). Society change and change in family violence from 1975 to 1985 as revealed by two national surveys. Journal of Marriage and the Family, 48, 465-479.

Szinovacz, M.E. (1983). Using couple data as a methodological tool: The case of marital violence. Journal of Marriage and the Family, 45, 623-644.

Tenopyr, M. L. (1999). Social science evidence in the courtroom: Daubert and beyond? Psychology, Public Policy, and Law, 5, 194-202.

Walker, L.E.A. (1984). Battered woman syndrome. New York: Springer.

Walker, L. E., \& Meloy, J. R. (1998). Stalking and domestic violence. In J. R. Meloy (Ed.), The psychology of stalking: Clinical and forensic perspectives (pp. 140-164). New York: Academic Press.

Webster, C., Harris, G., Rice, M., Cormier, C., \& Quinsey, V. (1994). The violence prediction scheme: Assessing dangerousness in high-risk men. Toronto, Ontario, Canada: University of Toronto Centre of Criminology. 


\section{FAMILY COURT REVIEW}

William G. Austin, Ph.D., is a licensed psychologist in Colorado and North Carolina and has a private practice in Northwest Colorado. He is also a past assistant professor of psychology at the University of Virginia and is a past Russell Sage Foundation Resident Fellow at University of Virginia School of Law. 